\title{
A Design and Implementation of the Online Curriculum System Based on the Browser/Server Architecture
}

\author{
Bing Chen ${ }^{1, a}$, Junhua Yao ${ }^{2, b}$ and Pin Wang ${ }^{1, c,{ }^{*}}$ \\ ${ }^{1}$ School of Mathematics and Information Science, Guangxi college of Education, Nanning, Guangxi, \\ 530023, China \\ ${ }^{2}$ China Electronic Port Data Center Nanning Branch, Nanning, Guangxi, 530821, China \\ c1040168586@qq.com \\ ${ }^{*}$ Corresponding author: Pin Wang
}

Keywords: online curriculum, the system analysis, system design, ADO.NET.

\begin{abstract}
This paper proposed the design idea and the development of an online curriculum system based on the Browser/Server architecture from the perspectives of system analysis and design. This system can efficiently manage and update the teaching contents. To solve the difficulty traditional online curriculum facing, the system offers the non-computer professional teachers a convenient platform for the online communication, easy development and maintenance.
\end{abstract}

\section{Introduction}

Booming online education brings growing popularity among people. Despite the optimistic prospect, the application is daunting that can be summarized in four major problems: 1 . Attaches greater importance to the teaching content than the design of learning environment and learning activities; 2. Low-frequency of content update; 3. Difficulty of non-computer professional teachers participating in the online curriculum producing; 4. High cost and low develop efficiency. According to the above problems, this paper expounds the design and development process of the system from perspectives of system analysis, system design based on research of network curriculum system of $\mathrm{B} / \mathrm{S}$ architecture.

\section{System Analysis}

\subsection{Goals}

With the help of the online curriculum system, course teacher can create the high-quality curriculum website by relaxing the technical entry.

\subsection{The Functional Requirement}

Autonomous Learning

The system provides the navigation bar by which the user can click directly to corresponding page and then display the contents, facilitating students choosing chapter of courses freely.

Multimedia Course Content

Based on to the teaching goal, it will present the audio-visual information and update in time.

Interactivity of Study Way

This system contains an online communication module, offering teachers and students a communicate tool without the limitation of the space and time.

Test of study effect

The system provides online testing module, consisting of the question self-generation, answer submission, and grading, etc.

\subsection{The design of object-oriented database}

Database design plays the important role in the system. A bad design causes slow query and poor performance.. 
Based on object-oriented model, this system contains the following tables: the backend management user table, the system information table, the navigation information table, the class table and students information table, curriculum subjects table, grades table, contents table, curriculum content, BBS section table, BBS major poster table and BBS reply poster table.

\section{4 Operation Environment and Development Tools}

Based on the Microsoft Net Framework 2.0, this system is developed mainly by C\#, and some by JavaScript, HTML. ADO.NET bridges between the database application and database, mainly providing object-oriented data access architecture to develop the database application.

Microsoft SQL Server2000 is chosen as the backend database due to the excellent performance. MS SQL relational database engine is a popular, highly extensible and reliable data storage engine, which offers the extensible database programming functionality based on web, the high efficiency and the security to access and process the data.

Visual Studio 2008 is chosen as the integrated development environment for this sysem, which integrates the features of design, source editor, graphic interface design, automated code generation and compilation. Meanwhile it offers the enhanced programming language, designer and editor and the data related new features, enable to accomplish the task in each software development cycle. It is a truly powerful IDE.

\section{The Design of System}

\subsection{The Development of Three-layer architecture}

The whole system framework adopts three-layer architecture to manage code and separates the logic layer and data layer with strong commonality and openness, for better project management and daily maintenance in the future. The architecture is divided into three layers: presentation layer, business logic layer and data access layer. (Shown in figure 1)

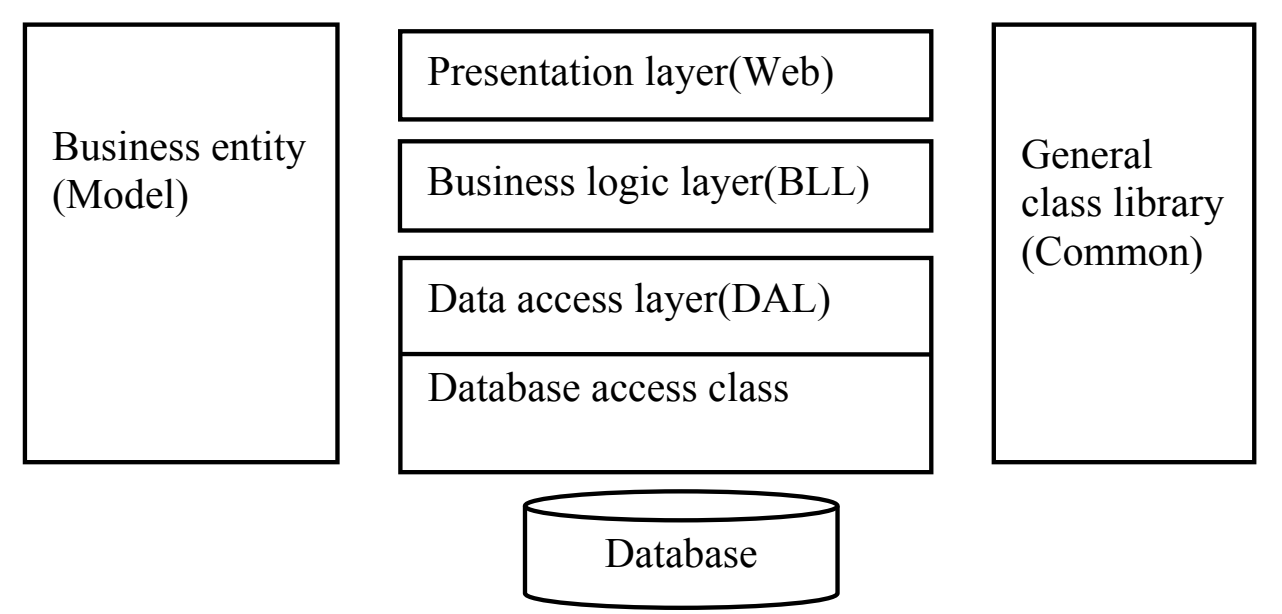

Figure1 The whole three-layer structure

The Presentation layer (Web): used for user interaction, receiving user request or returning to display of user request data results.

Business logic layer (BLL): works as a transition dealing with the interacted data to achieve business goals.

Data access layer (DAL): used for interaction and visiting with the database and access to data from database or save the data to the partial database.

Business entity (Model): used for encapsulating data structure entity including map database table or view, to describe the business objects of objective existence and function of branch layer. 
General class library (Common): used as general auxiliary tools, including encapsulation and validation, query, such as code for MD5 encryption, pinyin initials transformation, branch paging, etc.

Database access class: is the encapsulation of ADO.NET meaning encapsulating some common repeated database operations to one class.

\section{2 Module Division of System Function}

This system is divided into the frontend display and backend management.

\subsubsection{The Foreground Display Module}

The frontend of system provides a friendly interface and navigation menu for improving the students' learning efficiency. In order to unify the page style of online courses, this system employs new MasterPage version of ASP.NET 2.0 to define interface layout and apply integrated layout and appearance of the page. Therefore, students can login in online communica tion system or online examination system at the frontend page after registration. (Shown in figure 2)

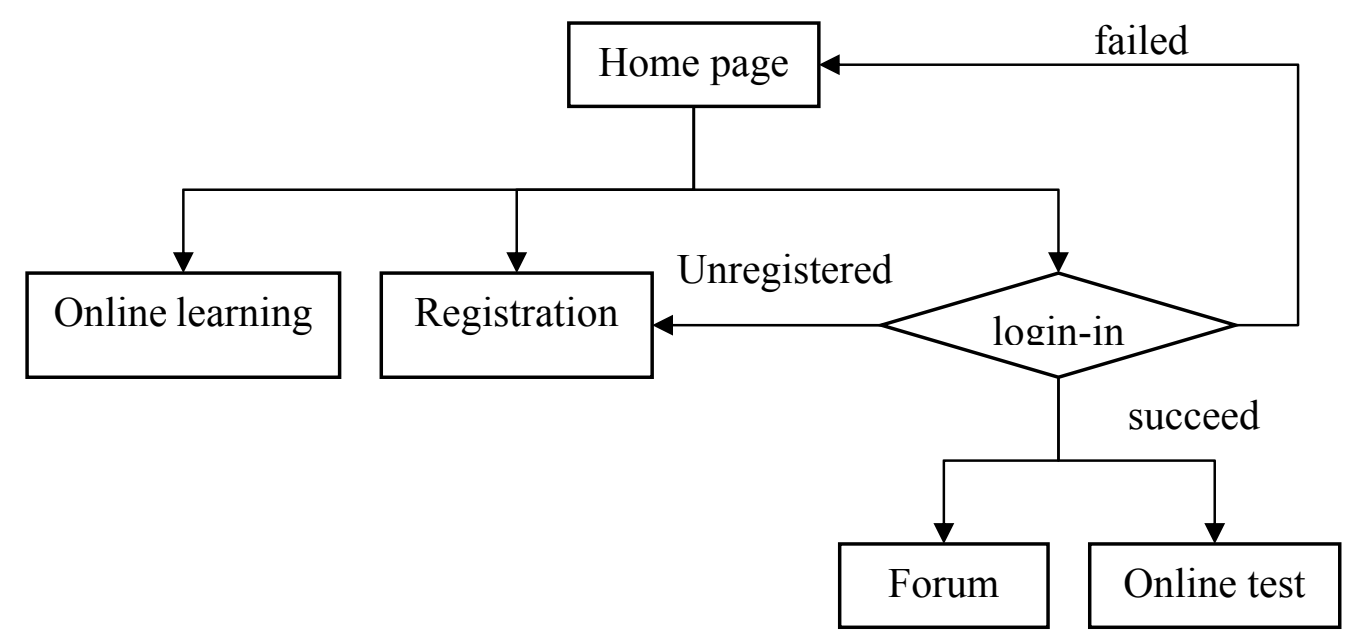

Figure 2 The operation of Foreground page

\subsubsection{The Backend Management Module}

According to the actual application, the backend management system consists of system management, navigation settings, student information management, examination system, BBS management, curriculum content publishing.

System management: including the system setting, the addition, deletion and modification from the backend administrator.

Navigation settings: addition, modification and the deletion of the course content node before the publishing.

Student information management: managing the student information registered in the frontend. The system administrator can also add, modify and delete the information from the backend directly.

Online examination module: implementing the examination major management, adding the test questions, and the grading maintenance and management.

BBS communication module: setting the boards of the forum, managing the board information, setting the moderator and the user access rights.

Course content publishing: the webpage editor FCKeditor is chosen to implement the visual content editing. The tool menus offered by the editor is very similar to Word frequently used by the teachers. The teachers can edit the course contents by the way of "What you get is what you see".

The system flowchart of the backend management system is shown as figure 3 : 


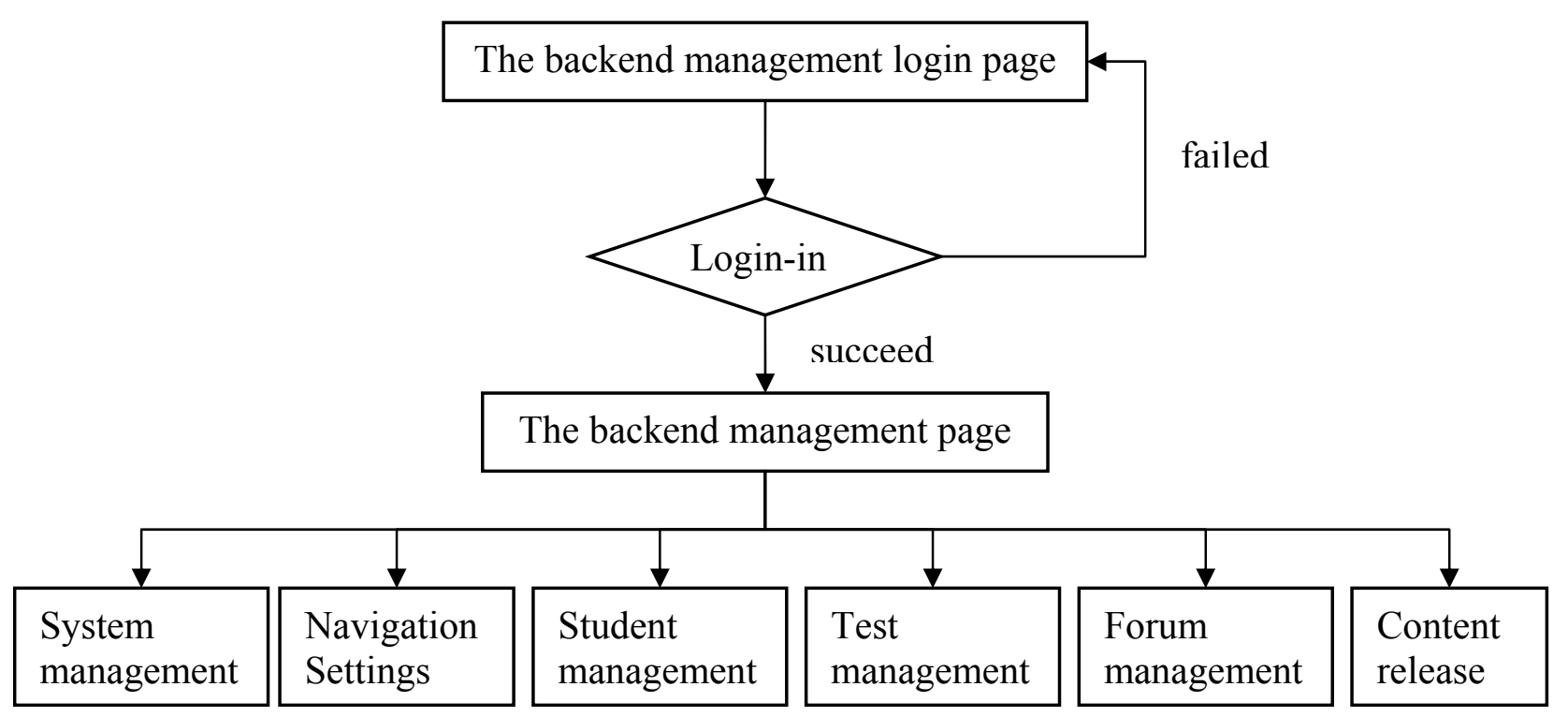

Figure 3 The operation of backend management

\section{The Result Analysis}

Traditional teaching course needs continuously updating, so does the online curriculum. Teachers in every school year or semester will add or modify the content. However, as the traditional online course update of teaching content is very difficult, teachers should master certain computer skills. The teachers can choose this system to release the online courses for the better management, as they can login in the backend page as an administrator, go to the course content management page, and do the curriculum maintenance.

\section{Conclusion}

In the online curriculum system, teachers can enjoy the rights of the design of the online curriculum without professional computer knowledge, which expel teachers from directly involving in curriculum design before. And it enables teachers to directly put their teaching design into the online curriculum design, to improve the present teaching attaching greater importance to online teaching than to teaching design. The online curriculum system aims to meet the present demand and be more scientific, reasonable, safe and flexible and versatile, easy to use in the future.

\section{Acknowledgement}

This study is supported by the Education Science fund of the Education Department of Guangxi, China (No.: 2013JGA272), and Guangxi Provincial Natural Science Research Project for Universities (No.: KY2015YB338). and the Education Science fund of the Guangxi Educational College, China (No.: XJJG15A03).

\section{References}

[1] Jia Zongxing, 2015, "The design and construction of document management system based on ASP.NET", Journal of Agricultural Network Information, pp.56-58.

[2] Li Dong, Wang Huaji, 2014, “General online test system based on B/S mode”, Shangqiu Vocational College Journal, pp. 29-31

[3] Li Tianping, 2012, NET in the Project, Electronic Industry Press: Beijing.

[4] Zhao Xiaojun, 2010, "The design and construction of network teaching system based on B/S structure", Journal of Computer and modernization, pp. 8-12

[5] Zhou Changfa, 2007, C \# Object-oriented Programming, Electronic Industry Press: Beijing. 